\title{
Investigation of the Chitosan Immobilized Eggshell for the Biosorption of Brillant Blue $R$ Dye
}

\author{
Buket Bulut Kocabas ${ }^{1}$ (i) Ilknur Tosun Satir ${ }^{2}$ \\ ${ }^{1}$ Yildız Technical University, Department of Chemistry, Istanbul, Turkey \\ ${ }^{2}$ Hitit University, Department of Chemistry, Corum, Turkey
}

\section{ABS T R ACT}

$\mathrm{T}$ The biosorption method for controlling water pollution can be considered as an alterna1 tive method for the pollution of synthetic paints. In this study, the removal of Brillant Blue R (BBR) dyestuff, which is a textile dyestuff, by biosorption is investigated. For this purpose, eggshell immobilized with chitosan (ESIC) is designed as a biosorbent. The biosorption mechanism was studied in batch and continuous mode. As far as the batch system is concerned, the following results have been obtained: The optimum $\mathrm{pH} 2$, dye concentration $25 \mathrm{ppm}$, interaction time 60 minutes, biosorbent amount $2.0 \mathrm{~g} / \mathrm{L}$, removal real wastewater $53.28 \%$. Regarding continuous systems, the following flow speed of 0.5 $\mathrm{mL} / \mathrm{min}$, biosorbent amount $2.0 \mathrm{~g} / \mathrm{L}$, removal real wastewater $91.01 \%$. Also, recycle experiments showed that there was $24.11 \%$ loss in the biosorption capacity of ESIC for BBR dye after 7 times reuse. Obtained results were consistent with Langmuir and Freundlich isotherm models. All the results demonstrate that ESIC is a natural, recyclable and costeffective biosorbent for BBR dye removal in wastewater.

\section{Keywords:}

Biosorption; BBR; Eggshell; Chitosan; Dye.

\author{
Article History: \\ Received: 2019/09/18 \\ Accepted: 2019/12/04 \\ Online: 2019/12/31 \\ Correspondence to: IlknurTosun Satir, \\ Hitit University, Chemistry, 19040, Corum, \\ TURKEY \\ E-Mail: ilknurtosun@hitit.edu.tr \\ Phone: +905306561603 \\ Fax: +903642277005
}

\section{INTRODUCTION}

ince dyes are colored compounds, they are one of $\checkmark$ the most easily recognizable contaminants in the environment. These compounds are found in many areas of the industry like: textile, color photography, cosmetics, paper, printing, plastic, food, etc. for product coloring (1-4). The fact that dye is poisonous reveals how important it is to remove dye from wastewater in terms of ecology $(5,6)$.

The discharge of dyes is carried out using a variety of methods such as biological degradation, membrane technologies, coagulation-flocculation, electrochemical techniques, advanced oxidation, chemical flocculation and precipitation, electrochemical, membrane filtration, ion exchange, aerobic, anaerobic and biosorption methods(7-9). Apart from these methods, the biosorption technique has been very popular in recent years in terms of chromatographic processes $(10,11)$.

For the first time, the adsorption method was introduced by Scheele in 1773 and Abbe Fontana in 1777 (12). Adsorption can be defined as the increase of surface concentration by attaching atoms, ions, and molecules to a solid surface (13). Several different natural and waste adsorbents have been investigated to remove many pollutants by adsorption $(14,15)$. Biosorption is defined as the collection of selected ions on biomass (16). Biosorption is also the most promising technique for removing dyes in terms of simplicity, cost-efficiency, and insensitivity to toxic environments (17-19).

Chitosan is a substance found naturally in the exoskeleton of insects and in the shell of the mushroom cell walls of shellfish. Chitosan is a polysaccharide widely present in nature. It has a high number of hydroxyl and amino groups in the structure due to the repeating $\beta$ - $(1 \rightarrow 4)$ - linked glucosamine groups. Due to its advantageous properties of being nontoxic and enzymatically biodegradable chitosan is widely used in pharmaceutical and medical, wastewater treatment, biotechnology, cosmetics, food processing, agriculture and textile industries (20-22).

Eggshell is a natural material consisting of approximately 7000-17000 pores and calcium carbonate $(23,24)$. The fact that the eggshell is biodegradable, inexpensive and abundant material, it is an ideal alternative biosorbent, especially as the discharge of dyes and harmful inorganic ions. In addition, egg shell's natural porosity 
<smiles>CCOc1ccc(Nc2ccc(C(=C3C=CC(=[N+](CC)CC)C=C3)c3ccc(N(CC)Cc4cccc(S(=O)(=O)[O-])c4)cc3)cc2)cc1</smiles>

Figure 1. Chemical Structure of Brilliant Blue R Dye.

and high adsorptive capacity enable it to be an effective biosorbent to discharge dye from wastewater $(25,26)$.

In this study, biosorption of BBR dye known as textile dyestuff was analyzed onto ESIC biosorbent from wastewater. Effects of biosorbent amount, contact time, initial $\mathrm{pH}$, adsorbate amount, the effect of different ion, temperature, biosorption-desorption cycle were studied via a batch system and flow rate, amount of biosorbent and real wastewater were studied in the continuous system. The biosorption of ESIC was investigated with different kinetics and isotherm models. In addition, BBR dye removal was analyzed in real wastewater taken from a factory in Corum.

\section{MATERIAL AND METHODS}

\section{Preparation of ESIC}

Chitosan biopolymer used in the studies was purchased from Sigma-Aldrich and Eggshell was obtained from a local market. The eggshells were washed several times with distilled water to remove impurities and then dried in an oven at $40^{\circ} \mathrm{C}$. The laboratory mill was used to grind the eggshells. Eggshell powders and chitosan were mixed with a 1:1.5 mass ratio and homogenized in $75 \mathrm{~mL}$ $5 \%(\mathrm{v} / \mathrm{v})$ solution of acetic acid. The obtained suspension was injected into $500 \mathrm{~mL} 0.5 \mathrm{M}$ solution of $\mathrm{NaOH}$ and eggshell-chitosan particles were washed several times with pure water and dried for 24 hours at $50^{\circ} \mathrm{C}$. A grinder was used to obtain dried particles with a size below 150 $\mu \mathrm{m}(27)$.

\section{Dye Solutions}

In this study, an acidic Brilliant Blue R (BBR) dye was used. Its molecular weight is $825.96652 \mathrm{~g} / \mathrm{mol}$ and the molecular formula is $\mathrm{C}_{45} \mathrm{H}_{44} \mathrm{~N}_{3} \mathrm{NaO}_{7} \mathrm{~S}_{2}$. Fig. 1 shows the chemical structure of Brilliant Blue R (BBR) dye. The concentration of the dye solutions used in the study ranged between 50-1000 mg/L. For the adjustment of their $\mathrm{pH} 0.1 \mathrm{M} \mathrm{HCl}$ and $0.1 \mathrm{M} \mathrm{NaOH}$ solutions were used.

\section{Biosorption Experiments}

Firstly, the effect of different parameters was investigated in the batch systems. Those parameters are the biosorbent mass, interaction time, ionic strength, $\mathrm{pH}$ (between $1-10)$, temperature and dye concentration. For the $\mathrm{pH}, 0.1$ $\mathrm{g}$ of biosorbent was added to a $50 \mathrm{~mL} 25 \mathrm{mg} / \mathrm{L}$ solution of dye and the mixture was stirred for 60 minutes at 200 rpm. After centrifuging the mixture of the dye and the biosorbent at $3000 \mathrm{rpm}$ for 5 minutes, solid and liquid phases were separated. Absorbances at $586 \mathrm{~nm}$ wavelength were measured in order to determine the amount of the dye. The optimum biosorbent dosage between the range of $0.2-8.0 \mathrm{~g} / \mathrm{L}$ was investigated. Interaction time was studied at 3 different temperatures $\left(25,35\right.$ and $\left.45^{\circ} \mathrm{C}\right)$ in 5-90 minutes. So as to designate the effect of ionic strength on biosorption, it was adjusted using sodium chloride $(\mathrm{NaCl})$ between 0.02 and $0.5 \mathrm{M}$.

BBR biosorption onto ESIC in aqueous media was performed also in a continuous system. It was supported with glass-wool placed on biosorbent in a column. A peristaltic pump was used to provide solution flow. Biosorbent amount and flow rate were studied in a continuous system. Besides, BBR biosorption from real wastewater was investigated in a continuous system.

\section{Data Evaluation}

The following equation was used to find the biosorption capacity, $\mathrm{q}_{\mathrm{e}}(\mathrm{mg} / \mathrm{g})$;

$q_{e}=v \frac{\left(\mathrm{c}_{0}-\mathrm{c}_{\mathrm{e}}\right)}{m}$

In the formula,

$c_{0}(\mathrm{mg} / \mathrm{L})$ : The starting concentration of dye,

$c_{e}$ (mg/L): The dye concentration after biosorption,

$v$ (L): The volume of biosorption setting,

$m$ (g): The biosorbent amount.

\section{RESULTS AND DISCUSSION}

\section{The Effect of pH at Batch System}

The study was carried out with solutions having different $\mathrm{pH}$ values (from 1 to 10 ) since $\mathrm{pH}$ is a quite effective parameter in biosorption studies and Fig. 2 shows the results.

The biosorption capacity of the ESIC was high at low $\mathrm{pH}$ (maximum biosorption at $\mathrm{pH}=2$ ) but decreased at $\mathrm{pH}$ 


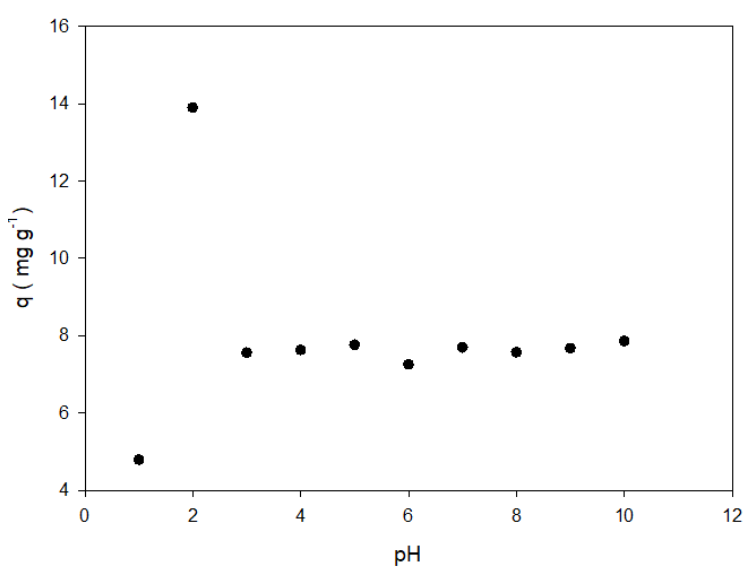

Figure 2. Investigation of $\mathrm{pH}$ on biosorption.

values higher than 4 . This result is due to the positive charge of the surface at lower $\mathrm{pH}$ values and a negative charge at higher values. At $\mathrm{pH}=2$, the hydronium ions present in the medium excessively forming hydrogen bonds with the oxygen in the $\mathrm{SO}_{3}$ - group on BBR. The capacity of the biosorption showed a decrease at $\mathrm{pH}=1$. This result may be because of the dissolution of ESIC at high $\mathrm{pH}$ values. When the results are examined, it can be said that $\mathrm{pH}=2.0$ is the optimum value for BBR biosorption with ESIC.

\section{The Effect of Biosorbent Amount at Batch System}

Different ESIC amounts ranging between 0.2 - $8.0 \mathrm{~g} / \mathrm{L}$ were used to reveal the effect of the biosorbent amount on the yield. Fig. 3 shows the obtained results.

The biosorption yield increases from $0.88 \%$ to $95.73 \%$ by increasing the \% removal rate of the biosorbent from $0.2 \mathrm{~g} / \mathrm{L}$ to $4.0 \mathrm{~g} / \mathrm{L}$ and it was found almost constant for the amounts of biosorbents greater than $2.0 \mathrm{~g} / \mathrm{L}$. An increase of biosorption efficiency was observed as the biosorbent dosage increased since the area of the surface and the possible binding sites increased $(28,29)$. Thus, $2.0 \mathrm{~g} / \mathrm{L}$ biosorbent amount was determined as optimum.

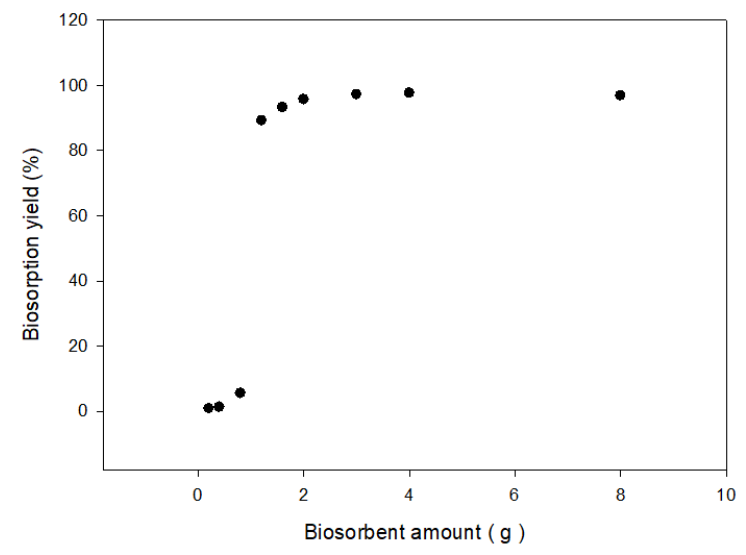

Figure 3. Investigation of biosorbent amount on biosorption.

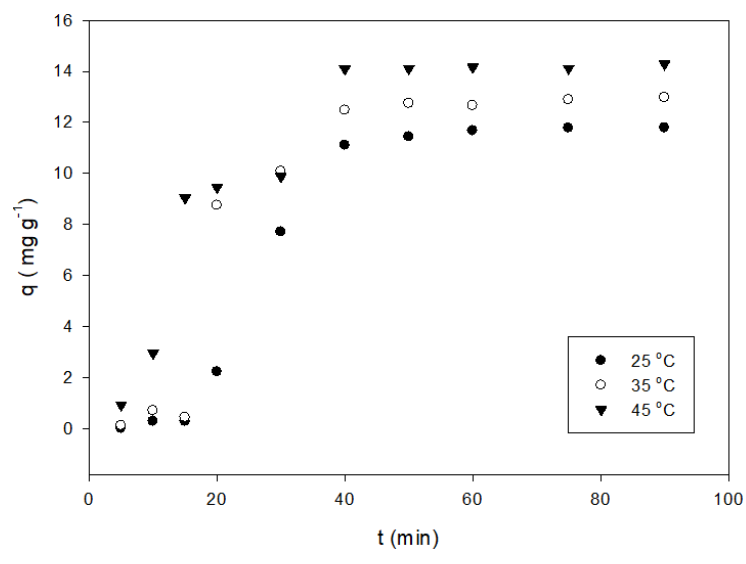

Figure 4. Investigation of interaction time and temperature on biosorption.

\section{The Effect of Interaction Time and Temperature at Batch System}

Different interaction times changing between 5 to $90 \mathrm{~min}$ were applied at three changing temperatures (25, 35 and $45^{\circ} \mathrm{C}$ ) to observe the effect of change in time and temperature on BBR biosorption. Fig. 4 shows that as the contact time increased, the biosorption capacity increased and then reached a constant value. The biosorption equilibrium was reached at $60 \mathrm{~min}$ at all three temperatures. The biosorption capacities were found to be $11.67 \mathrm{mg} / \mathrm{g}$ for 25 ${ }^{\circ} \mathrm{C}, 12.65 \mathrm{mg} / \mathrm{g}$ for $35^{\circ} \mathrm{C}$ and $14.16 \mathrm{mg} / \mathrm{g}$ for $45^{\circ} \mathrm{C}$.

\section{Biosorption Kinetics}

To determine the mechanism of the chemical reaction of the biosorption in the study, time-dependent data were evaluated by the pseudo-first-order (PFO) and pseudosecond-order (PSO) kinetic and intraparticle diffusion models.

According to Lagergren's PFO kinetic model (30), the rate of biosorption is linearly correlated to the number of vacancies on the biosorbent surface. According to this assumption, the relationship between the biosorption capacity and the duration of contact is given by the equation below.

$\frac{d q t}{d t}=k_{1}\left(\mathrm{q}_{\mathrm{e}}-\mathrm{q}_{\mathrm{t}}\right)$

In this formula:

$q_{e}(\mathrm{mg} / \mathrm{g}):$ The biosorbed dye amount at equilibrium,

$q_{t}(\mathrm{mg} / \mathrm{g})$ : The biosorbed dye amount at time $\mathrm{t}$,

$k_{1}$ (1/min): The rate constant for PFO model.

Taking advantage of this equation, when the values of $\ln \left(\mathrm{q}_{\mathrm{e}}-\mathrm{q}_{\mathrm{t}}\right)$ are plotted against $\mathrm{t}$, the slope is $-\mathrm{k}_{1}$ and the break- 


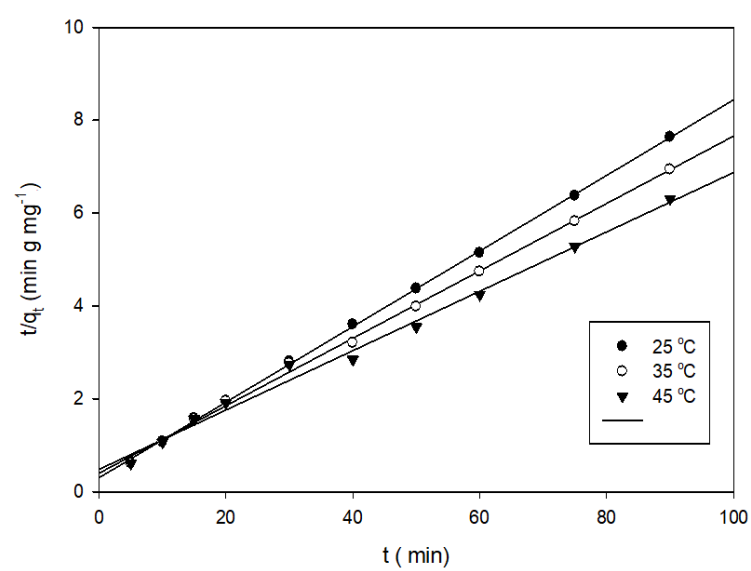

Figure 5. PSO kinetic models for BBR biosorption.

point is $\operatorname{lnq}_{\mathrm{e}}$. The $\mathrm{r}^{2}$ values, which represent the linearity of the graph, should be close to 1 .

$\frac{t}{q_{t}}=\frac{1}{k_{2} q_{e}^{2}}+\frac{1}{q_{e}} t$

is the linear expression of the equation.

Ho's PSO kinetic model of (31) is a model favored according to several investigators because it is simple and reasonable for representing the experimental results. The following equation expresses this kinetic model.

$$
\frac{d q t}{q d t}=k_{2}\left(\mathrm{q}_{\mathrm{e}}-\mathrm{q}_{\mathrm{t}}\right)
$$

In this formula: model,

$k_{2}$ (g/mg.min): The rate constant for a PSO kinetic

$\mathrm{q}_{\mathrm{t}}(\mathrm{mg} / \mathrm{g})$ : The biosorbed amount of dye at time $\mathrm{t}$,

$\mathrm{q}_{\mathrm{e}}(\mathrm{mg} / \mathrm{g})$ : Maximum biosorption capacity.

When this model is applied, the experimentally calculated $t / q_{t}$ values are plotted against $t$. As can be seen from Table 1 , the $\mathrm{r}^{2}$ values of the PSO kinetic model studies are between 0.991 and 0.999 depending on the temperature. The obtained data show that the variation in this range is linear, while the $\mathrm{q}_{\mathrm{e}}$ values are within acceptable limits, indicating that the PSO kinetic model is the most appropriate kinetic model for this study.

Weber-Morris diffusion equation is

$$
q_{t}=k_{p} \cdot t^{(1 / 2)}+C
$$

In this formula:

$q_{t}$ (mg/g): The amount of biosorption capacity at time t,

\section{$k_{p}\left(\mathrm{mg} / \mathrm{g} \cdot \mathrm{dk}^{1 / 2}\right):$ Intraparticle diffusion rate constant.}

Finally, the intraparticle diffusion kinetic model was applied to the biosorption of BBR on ESIC. Values of $\mathrm{r}^{2}$ between 0.884 and 0.921 indicate that the intraparticle diffusion kinetic model is not suitable (Table 1).

\section{Isotherms}

The results of the BBR biosorption experiment in the non-continuous system were examined with Dubinin-Radushkevich, Freundlich, and Langmuir isotherm models. The Langmuir isotherm implies that the biosorbent has a uniform structure and single-layer biosorbent occurs on the surface. After the biosorption process, the surface monolayer is coated and the amount of biosorbent material is fixed. Langmuir isotherm model (32) equation is

$$
\frac{1}{q_{e}}=\frac{1}{q_{\max }}+\left(\frac{1}{q_{\max } K_{L}}\right) \cdot \frac{1}{c_{e}}
$$

In the formula:

$q_{\max }(\mathrm{mg} / \mathrm{g}):$ Maximum monolayer biosorption capacity,

$c_{e}$ (mg/L): The amount of dye at equilibrium,

$K_{L}$ (L/mol): The Langmuir biosorption equilibrium constant.

The $R_{L}$ (dispersion) constant is calculated to explain the equilibrium mechanism of biosorption and in order to

\begin{tabular}{|c|c|c|c|c|c|c|c|c|c|}
\hline \multirow[t]{2}{*}{$\begin{array}{c}\text { Temperature } \\
\left({ }^{\circ} \mathrm{C}\right)\end{array}$} & \multicolumn{3}{|c|}{ PFO } & \multicolumn{3}{|c|}{ PSO } & \multicolumn{3}{|c|}{ Intraparticle diffusion } \\
\hline & $\begin{array}{c}k_{1} \\
(1 / \mathrm{min})\end{array}$ & $\begin{array}{c}q_{e} \\
(m g / g)\end{array}$ & $R^{2}$ & $\begin{array}{c}k 2 \\
(\mathrm{~g} / \mathrm{mg} \cdot \mathrm{min})\end{array}$ & $\begin{array}{c}q e \\
(m g / g)\end{array}$ & $R^{2}$ & $\begin{array}{c}k p \\
\left(m g / g \cdot \min ^{1 / 2}\right)\end{array}$ & $\begin{array}{c}C \\
(m g / g)\end{array}$ & $R^{2}$ \\
\hline 25 & $7.0 \times 10^{-2}$ & 7.86 & 0.892 & $2.18^{\times} 10^{-2}$ & 12.345 & 0.999 & 0.495 & 7.660 & 0.914 \\
\hline 35 & $8.6 \times 10^{-2}$ & 9.924 & 0.892 & $1.29 \times 10^{-2}$ & 13.888 & 0.997 & 0.698 & 7.078 & 0.921 \\
\hline 45 & $11.6 \times 10^{-2}$ & 21.37 & 0.820 & $8.23^{x} 10^{-3}$ & 15.87 & 0.991 & 0.994 & 6.445 & 0.884 \\
\hline
\end{tabular}
check if biosorption is voluntary, the following equation is

Table 1. Biosorption kinetic parameters of BBR onto ESIC. 


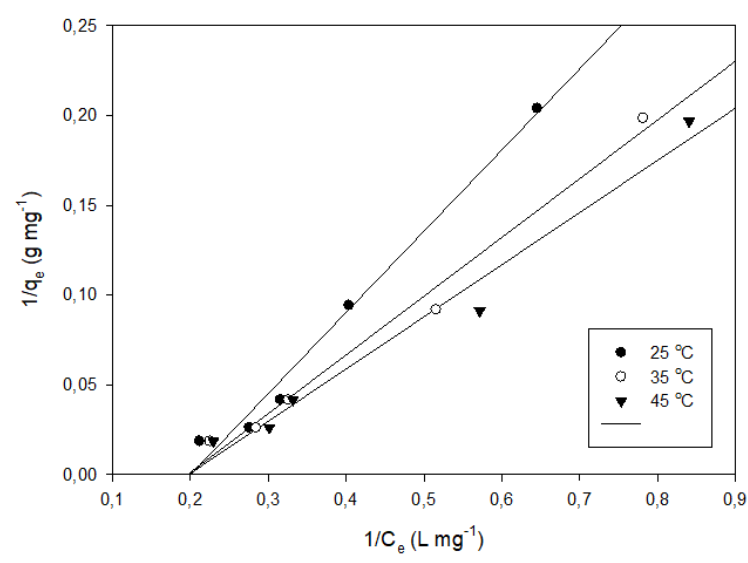

Figure 6. Langmuir isotherm for BBR biosorption onto ESIC.

used:

$$
R_{L}=\frac{1}{1+K_{L} c_{0}}
$$

In the formula:

$$
\begin{aligned}
& K_{L}(\mathrm{~L} / \mathrm{mg}) \text { : Langmuir isotherm constant, } \\
& C_{0}(\mathrm{mg} / \mathrm{L}) \text { : Starting concentration of the biosorbent. }
\end{aligned}
$$

Calculated $\mathrm{R}_{\mathrm{L}}$ value between 0 and 1 , shows that the biosorption takes place spontaneously (32). When $\mathrm{r}^{2}$ values of the biosorption data in Table 2 are compared, it is seen that the BBR is in accordance with the Langmuir isotherm model on the biosorption of ESIC. This demonstrates that the biosorption process can be single-ply and homogeneous.

According to Freundlich (33), the biosorption regions on the surface of a biosorbent are heterogeneous. Thus, they consist of different types of biosorption sites. The mathematical expression of Freundlich isotherm is

$$
\ln q_{e}=\ln K_{F}+\frac{1}{n} \ln C_{e}
$$

In this formula:

$$
\begin{aligned}
& K_{F}(\mathrm{~L} / \mathrm{g}): \text { Freundlich biosorption isotherm constant, } \\
& \frac{1}{n} \text { (dimensionless): The biosorption intensity, } \\
& q_{e}(\mathrm{~m} / \mathrm{g}) \text { : Biosorption capacity at equilibrium, } \\
& C_{e}(\mathrm{mg} / \mathrm{L}): \text { The amount of dye at equilibrium. }
\end{aligned}
$$

Usually, $\mathrm{n}$ as an indication of good adsorption is between 1 and 10 . The value of $1 / n$, which takes values in the range $0-1$, is the heterogeneity factor and its value reaches to zero when the surface is more heterogeneous.

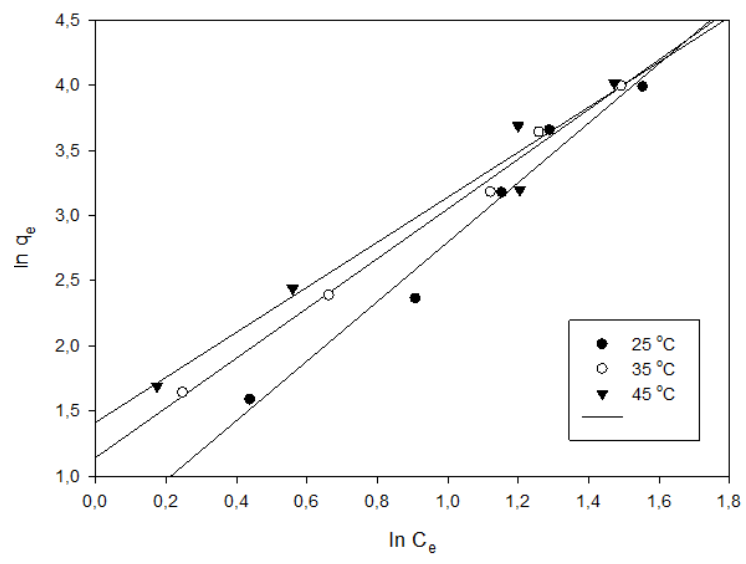

Figure 7. Freundlich isotherm for BBR biosorption onto ESIC.

According to the Freundlich isotherm model, $\mathrm{K}_{\mathrm{F}}$ value is found between 1.673 and 4.039. When $\mathrm{n}$ is greater than 1 , the process of biosorption is self-driven.

D-R model (34) allows to understand if the adsorption is physical or chemical. It is assumed that the energies of the eclipsed sites in this isotherm are like the Gaussian distribution. Ionic species are first connected to the energetically most suitable regions. While multi-layer biosorption occurs on these bonding ions, the D-R isotherm is calculated by the following equation:

$$
\operatorname{In} q_{e}=\operatorname{In} q_{m}-\beta \varepsilon^{2}
$$

In this formula:

$q_{m}(\mathrm{mg} / \mathrm{g})$ : The maximum biosorption capacity,

$\beta$ : Constant gives mean free energy $(\mathrm{E})$.

By applying the following equation:

$$
E=-2 \beta^{(1 / 2)}
$$

To obtain the Polanyi potential $\varepsilon$, the following equation is used;

$$
\varepsilon=R T \ln \left(1+\frac{1}{c_{e}}\right)
$$

In the formula:

$T(\mathrm{~K}):$ The absolute temperature,

$R$ : The gas constant $(8,314 \mathrm{~kJ} / \mathrm{mol})$,

$\varepsilon$ : The Polayni potential.

Examination of the $\mathrm{r}^{2}$ values of the biosorption data in Table 2 reveals that the adsorption of BBR on ESIC does not conform to the Dubinin-Radushkevich isotherm model. 
Table 2. Biosorption isotherm values of BBR onto ESIC.

\begin{tabular}{|c|c|c|c|c|c|c|c|c|c|c|c|}
\hline \multirow{2}{*}{$\begin{array}{c}\text { Temperature } \\
\left({ }^{\circ} \mathrm{C}\right)\end{array}$} & \multicolumn{4}{|c|}{ Langmuir } & \multicolumn{3}{|c|}{ Freundlich } & \multicolumn{4}{|c|}{ Dubinin-Radushkevich (D-R) } \\
\hline & $\begin{array}{c}q_{\max } \\
(\mathrm{mol} / \mathrm{g})\end{array}$ & $\begin{array}{c}K_{L} \\
(L / m o l)\end{array}$ & $r^{2}$ & $R_{L}$ & $n$ & $\begin{array}{c}K_{F} \\
(L / g)\end{array}$ & $r^{2}$ & $\begin{array}{c}q_{m} \\
(m o l / g)\end{array}$ & $\begin{array}{c}\beta \\
\left(\mathrm{mol}^{2} / \mathrm{k} J^{2}\right)\end{array}$ & $r^{2}$ & $\begin{array}{c}E \\
(k J / m o l)\end{array}$ \\
\hline 25 & 11.11 & $19.9 \times 10^{-2}$ & 0.984 & 17.02 & 2.282 & 1.673 & 0.973 & 61.74 & 1.787 & 0.894 & 0.529 \\
\hline 35 & 15.62 & $19.96 \times 10^{-2}$ & 0.986 & 7.82 & 1.907 & 3.142 & 0.994 & 55.924 & 1.174 & 0.929 & 0.652 \\
\hline 45 & 17.54 & $19.96 \times 10^{-2}$ & 0.976 & 6.87 & 1.705 & 4.039 & 0.984 & 55.20 & 9.671 & 0.937 & 0.227 \\
\hline
\end{tabular}

\section{Effect of Salt}

To observe the effect of salt on the biosorption, solutions were prepared to contain $\mathrm{NaCl}$ salt adjusted to a concentration range of $0.02-0.50 \mathrm{~mol} / \mathrm{L}$. The $\mathrm{pH}$, biosorbent amount and contact time of prepared solutions were 2.0; $2.0 \mathrm{~g} / \mathrm{L}$ and $60 \mathrm{~min}$, respectively. The dye concentration of the solutions was chosen as $25 \mathrm{mg} / \mathrm{L}$. Fig. 8 shows the obtained results.

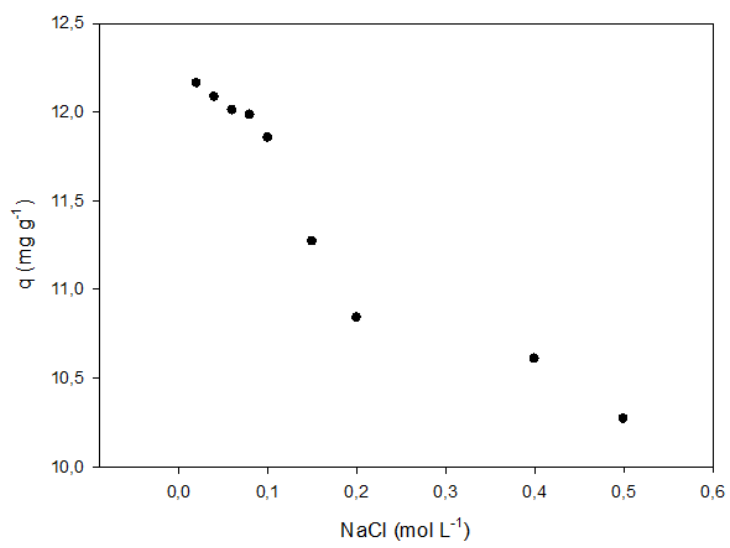

Figure 8. Salt effect on the BBR biosorption onto ESIC.

The results show that an increase in salt concentration yields a considerable decrease in biosorption. This is due to the accumulation of other ions in the environment on the biosorbent surface.

\section{Biosorption Thermodynamics}

Gibbs free energy change $\Delta G^{\circ}$, standard enthalpy $\Delta H^{\circ}$ and standard entropy change $\Delta S^{\circ}$ are important thermodynamic parameters. They are used to understand the effect of temperature on the biosorption process and to determine the necessary dynamic forces. The relation between the $K_{L}$ constant obtained from the Langmuir isotherm model and $\Delta \mathrm{G}^{\circ}$ is shown below:

$$
\Delta G^{0}=-R T \operatorname{In} K_{L}^{0}
$$

As a result of the Gibbs equation with the combination of Equation 12, the relation between $\Delta H^{o}$ and $\Delta S^{o}$ and $K_{L}$ is obtained as:

$$
\operatorname{In} K_{L}=-\frac{\left(\Delta H^{0}\right)}{R T}+\frac{\left(\Delta S^{0}\right)}{R}
$$

In the formula:

$$
K_{L}(\mathrm{~L} / \mathrm{mol}) \text { : Langmuir isotherm constant. }
$$

The negative value of $\Delta \mathrm{G}^{\circ}$ is an indication that the reaction is exothermic as $\Delta H^{\circ}$ The entropy change $\Delta S^{\circ}$ explains the irregularity of the reaction. As a result of a positive $\Delta \mathrm{S}^{\circ}$, the irregularity of the dye molecule increases.

Thermodynamic parameters of biosorption of BBR with ESIC were evaluated by analyzing $\Delta \mathrm{G}^{\circ}, \Delta \mathrm{H}^{\circ}$, and $\Delta \mathrm{S}^{\circ}$. $K_{L}$ was used as the equilibrium constant. The thermodynamic data calculated by using the slope and the batch point of the line obtained by plotting $1 / \mathrm{T}$ against $\ln K_{L}$ are given in Table 3.

As seen in Table 3, free energy change has a negative value at all three temperatures. This shows that the biosorption reaction of the BBR onto the ESIC is spontaneous.

The positive change in enthalpy shows that the biosorption of BBR is endothermic. Entropy change also has a positive value enthalpy change. This indicates that the reaction mechanism increases the irregularity of the dye molecule.

\section{Column Biosorption Studies}

Flow rate, biosorbent content and actual wastewater parameters were investigated for biosorption of BBR dye in the continuous system. The effect of flow rate in a continuous system was studied by applying the rate between $0.50 \mathrm{~mL} / \mathrm{min}$ and $4.00 \mathrm{~mL} / \mathrm{min}$. Fig. 9 shows the change of the biosorption capacity with the flow rate of the so-

Table 3. Biosorption thermodynamic for BBR onto ESIC.

\begin{tabular}{cccc}
\hline$t\left({ }^{\circ} \mathrm{C}\right)$ & $\Delta G^{\circ}(\mathrm{kJ} / \mathrm{mol})$ & $\Delta H^{\circ}(\mathrm{kJ} / \mathrm{mol})$ & $\Delta S^{\circ}(\mathrm{J} / \mathrm{K} . \mathrm{mol})$ \\
\hline 25 & -13.586 & & \\
35 & -12.500 & 179.501 & 0.551 \\
45 & -2.355 & & \\
\hline
\end{tabular}




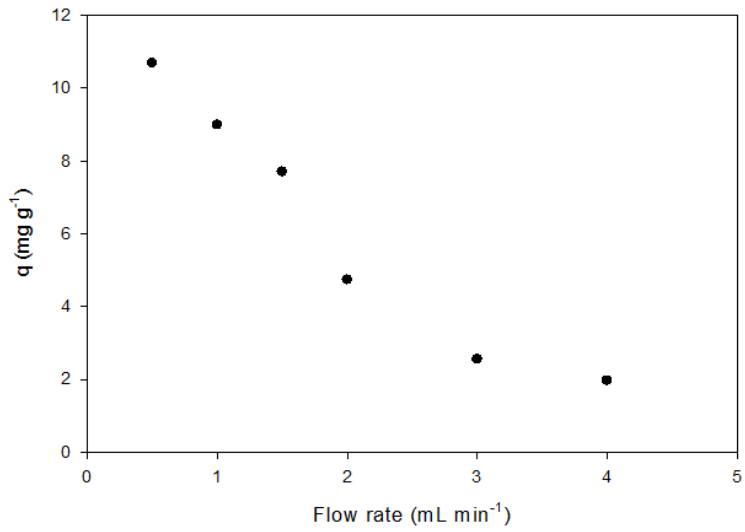

Figure 9. Flow rate change at continuous system.

lution.

An increase in flow rate significantly decreases the biosorption of BBR. The biosorption capacity at the lowest flow rate of $0.50 \mathrm{~mL} / \mathrm{min}$ was determined to be $11.44 \mathrm{mg} / \mathrm{g}$ The reason for the decrease of the biosorption capacity is the shorter contact time after increasing the flow rate. Because at high flow rates, holding the dye solution in the column becomes more difficult and the biosorption capacity decreases. However, at low flow rates, the dye solution is in contact with the biosorbent for a longer time. Thus, more dye can be removed. As a result, optimum flow rate for dye biosorption in continuous system was determined as 0.50 $\mathrm{mL} / \mathrm{min}$.

In the continuous system, dye biosorption was sought at a flow rate of $0.5 \mathrm{~mL} / \mathrm{min}$ at a range of biosorbent from $0.20 \mathrm{~g} / \mathrm{L}$ to $3.00 \mathrm{~g} / \mathrm{L}$. As a result of the investigated values, the change of dye removal \% by the amount of biosorption is given in Fig.10.

The process was carried out by using biosorbent in different amounts in the continuous removal process of the dye. The optimum amount of biosorbent was chosen as 2.00 $\mathrm{g} / \mathrm{L}$. When the amount of biosorbent was chosen as $3.00 \mathrm{~g} / \mathrm{L}$, biosorption removal was found to approach $100 \%$. As can be seen, BBR removal increased as the amount of biosorbent

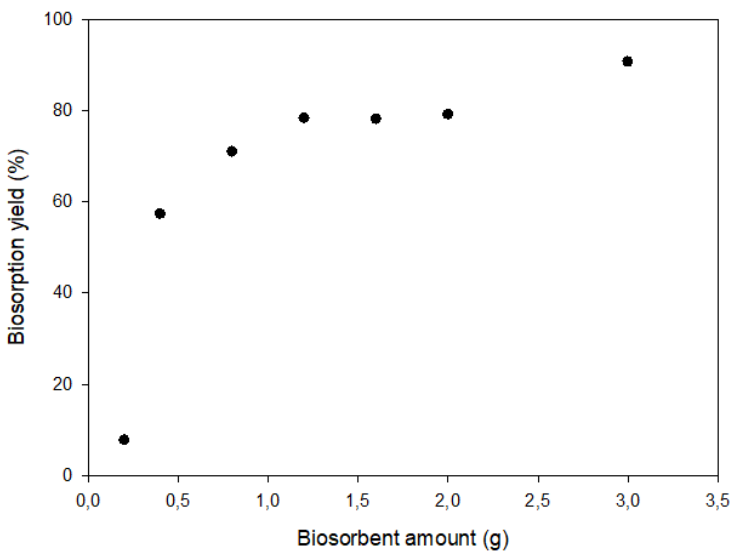

Figure 10. Change of biosorbent amount at continuous systemm.

increased because when the column diameter is kept constant, the column height increases along with the increase in the amount of biosorbent. The increase in column height leads to a longer contact time, which in turn causes the biosorbent and the sorbate to contact more of the column.

\section{Characterization of the Biosorbent}

SEM analysis of the ESIC used as a biosorbent in intermittent and continuous system studies has been performed to obtain information about the surface structure.

Fig. 11a shows that the surface of ESIC has a heterogeneous, rough and porous structure. Therefore, Fig. 11b shows that the surface of the ESIC biosorbent binds to different regions of the BBR.

\section{Desorption and Reusability}

After the BBR biosorption process on ESIC, cyclic desorption and reusability were investigated. The reusability of the biosorbent must be high to reduce the use of the biosorbent. Fig.12 shows the data from the biosorption-desorption cycle.

As can be seen, the biosorption-desorption cycling was

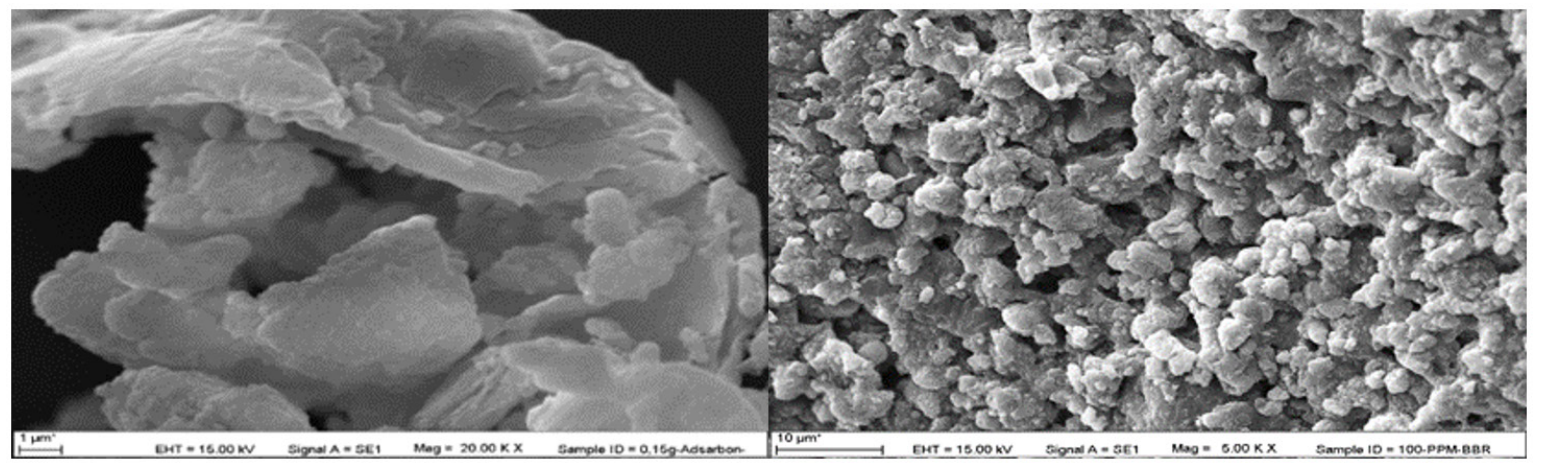

Figure 11. The SEM image of ESIC a) initial b) after biosorption. 


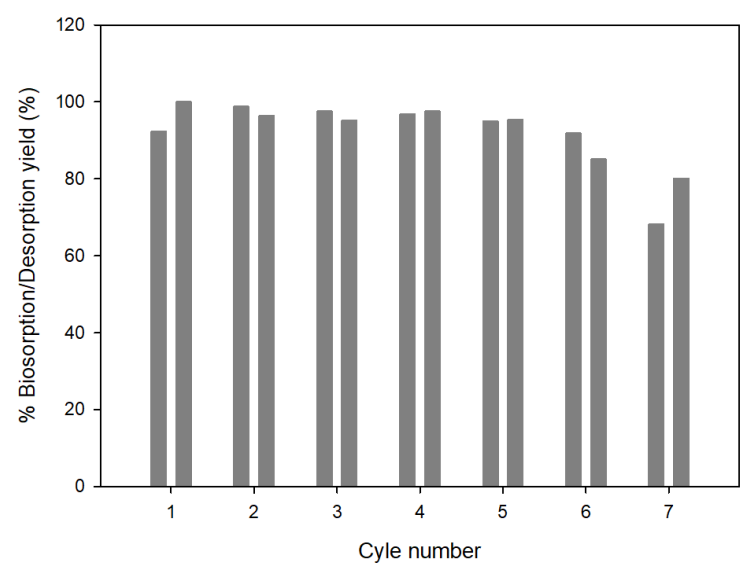

Figure 12. The reusability of ESIC.

carried out 7 times in the batch system. At the 7th cycle, a $24.11 \%$, reduction in biosorption efficiency was observed the effect was still being observed.

\section{Application to Real Wastewater}

Biosorption study with real wastewater containing 25 $\mathrm{mg} / \mathrm{L}$ BBR under optimum biosorption conditions $(\mathrm{pH}$ $=2 ; 2.0 \mathrm{~g} / \mathrm{L}$ biosorbent amount, $60 \mathrm{~min}$ contact time) determined for the removal of BBR in batch system in real wastewater conditions. The actual sample was taken from the wastewater of a factory. The biosorption process yielded $53.28 \%$ removal of the dye. It can be seen that the ESIC biosorbent can be used reliably in industrial environment for the removal of BBR.

Working conditions for a real wastewater sample containing $25 \mathrm{mg} / \mathrm{L} \mathrm{BBR}$ in the continuous system; $\mathrm{pH}=2 ; 0.10$ $\mathrm{g}$ of adsorbent amount; $50 \mathrm{~mL}$ of the dye solution and 0.50 $\mathrm{mL} / \mathrm{min}$. In this condition, the dye removal was $91.01 \%$. These results show that BBR removal in a real wastewater environment is highly efficient.

\section{CONCLUSION}

Eggshells are inexpensive and easily available biosorbent. Because of these properties, they can be used for the removal of BBR from aqueous solutions efficiently and costeffectively.

- With the developed biosorbent, the removal of BBR dyestuff in the real wastewater environment was carried out with high efficiency.

- For both systems, the maximum biosorption efficiency of $2.00 \mathrm{~g} / \mathrm{L}$ biosorbent amount was achieved for the concentration of $25 \mathrm{mg} / \mathrm{L}$ of dye.

- In the batch system, 60 minutes of mixing time were continuously operated and 100 minutes for the continuous system at the optimum flow rate $0.50 \mathrm{~mL} / \mathrm{min}$.

- Optimum dye removal rates for batch and continuous systems were determined as $95.73 \%$ and $78.21 \%$, respectively.

- $\quad$ The \% removal in the batch system remained constant by increasing the amount of biosorbent, however, it reached $100 \%$ in the continuous system. Taking all these results into consideration, it is seen that BBR in wastewater can be applied by biosorption of the removal of eggshell immobilized with chitosan.

\section{References}

1. Akar T, Tosun İ, Kaynak Z, Kavas E, Incirkus G, Akar ST. Assessment of the biosorption characteristics of a macro-fungus for the decolorization of Acid Red 44 (AR44) dye. Journal of Hazardous Materials 171(1) (2009) 865-871.

2. Elsherbiny AS. Adsorption kinetics and mechanism of acid dye onto montmorillonite from aqueous solutions: Stopped-flow measurements. Applied Clay Science 83-84(2013) 56-62.

3. Zhao X-g, Huang J-g, Wang B, Bi Q, Dong L-1, Liu X-j. Preparation of titanium peroxide and its selective adsorption property on cationic dyes. Applied Surface Science 292(2014) 576-582.

4. Hao OJ, Kim H, Chiang P-C. Decolorization of Wastewater. Critical Reviews in Environmental Science and Technology 30(4) (2000) 449-505.

5. Rauf MA, Shehadi IA, Hassan WW. Studies on the removal of Neutral Red on sand from aqueous solution and its kinetic behavior. Dyes and Pigments 75(3) (2007) 723-726.

6. Erol K, Köse K, Köse DA, Sızır Ü, Tosun Satır İ, Uzun L. Adsorption of Victoria Blue R (VBR) dye on magnetic microparticles containing $\mathrm{Fe}(\mathrm{II})-\mathrm{Co}(\mathrm{II})$ double salt. Desalination and Water Treatment 57(20) (2016) 9307-9317.

7. Mao J, Won SW, Choi SB, Lee MW, Yun Y-S. Surface modification of the Corynebacterium glutamicum biomass to increase carboxyl binding site for basic dye molecules. Biochemical Engineering Journal 46(1) (2009) 1-6.

8. Moradi SE. Microwave assisted preparation of sodium dodecyl sulphate (SDS) modified ordered nanoporous carbon and its adsorption for MB dye. Journal of Industrial and Engineering Chemistry 20(1) (2014) 208-215.

9. Shirzad-Siboni M, Khataee A, Joo SW. Kinetics and equilibrium studies of removal of an azo dye from aqueous solution by adsorption onto scallop. Journal of Industrial and Engineering Chemistry 20(2) (2014) 610-615.

10. Erol K. DNA adsorption via Co(II) immobilized cryogels. Journal of Macromolecular Science, Part A 53(10) (2016) 629-635.

11. Erol K. Polychelated cryogels: hemoglobin adsorption from human blood. Artificial Cells, Nanomedicine, and Biotechnology 45(1) (2017) 31-38.

12. Greg S, Sing K. Adsorption, surface area and porosity-Academic Press, New York, 1982

13. Juang RS, Wu FC, Tseng RL. The Ability of Activated Clay for the Adsorption of Dyes from Aqueous Solutions. Environmental Technology 18(5) (1997) 525-531.

14. Shen K, Gondal MA. Removal of hazardous Rhodamine dye from water by adsorption onto exhausted coffee ground. Journal of Saudi 
Chemical Society 21 (2017) 120-127.

15. Mittal A, Kaur D, Malviya A, Mittal J, Gupta VK. Adsorption studies on the removal of coloring agent phenol red from wastewater using waste materials as adsorbents. Journal of Colloid and Interface Science 337(2) (2009) 345-354.

16. Volesky B. Biosorption and me. Water Research 41(18) (2007) 40174029.

17. Ghaedi M, Mosallanejad N. Study of competitive adsorption of malachite green and sunset yellow dyes on cadmium hydroxide nanowires loaded on activated carbon. Journal of Industrial and Engineering Chemistry 20(3) (2014) 1085-1096.

18. Shan R-r, Yan L-g, Yang Y-m, Yang K, Yu S-j, Yu H-q, et al. Highly efficient removal of three red dyes by adsorption onto $\mathrm{Mg}-\mathrm{Al}$ layered double hydroxide. Journal of Industrial and Engineering Chemistry 21(2015) 561-568.

19. El-Mekkawi D, Galal HR. Removal of a synthetic dye "Direct Fast Blue B2RL" via adsorption and photocatalytic degradation using low cost rutile and Degussa P25 titanium dioxide. Journal of Hydro-environment Research 7(3) (2013) 219-226.

20. Agboh O, Qin Y. Chitin and chitosan fibers. Polymers for Advanced Technologies 8(6) (1997) 355-365.

21. Spulber R, Chifiriuc C, Fleancu M, Popa O, Băbeanu N. Antibacterial Activity of Magnetite Nanoparticles Coated with Bee Pollen Extracts. in."Agriculture for Life, Life for Agriculture" conference proceedings, pp.579-585, 2018 Sciendo.

22. Knaul JZ, Hudson SM, Creber KAM. Crosslinking of chitosan fibers with dialdehydes: Proposal of a new reaction mechanism. Journal of Polymer Science Part B: Polymer Physics 37(11) (1999) 1079-1094.

23. Wenming D, Zhijun G, Jinzhou D, Liying Z, Zuyi T. Sorption characteristics of zinc(II) by calcareous soil-radiotracer study. Applied Radiation and Isotopes 54(3) (2001) 371-375.
24. William J, Stadelman OJC. Egg science and technology, fourth ed. New York, Food Products Press, 1995.

25. Guru PS, Dash S. Sorption on eggshell waste-A review on ultrastructure, biomineralization and other applications. Advances in Colloid and Interface Science 209 (2014) 49-67.

26. Saha PD, Chowdhury S, Mondal M, Sinha K. Biosorption of Direct Red 28 (Congo Red) from aqueous solutions by eggshells: Batch and column studies. Separation Science and Technology 47(1) (2012) 112-123.

27. Ngah WW, Ab Ghani S, Kamari A. Adsorption behaviour of Fe (II) and $\mathrm{Fe}$ (III) ions in aqueous solution on chitosan and cross-linked chitosan beads. Bioresource technology 96(4) (2005) 443-50.

28. Gong R, Ding Y, Li M, Yang C, Liu H, Sun Y. Utilization of powdered peanut hull as biosorbent for removal of anionic dyes from aqueous solution. Dyes and Pigments 64(3) (2005) 187-192.

29. Gong R, Ding Y, Liu H, Chen Q, Liu Z. Lead biosorption and desorption by intact and pretreated spirulina maxima biomass. Chemosphere. 2005;58(1):125-30.

30. Lagergren S. Zur theorie der sogenannten adsorption geloster stoffe. Kungliga svenska vetenskapsakademiens Handlingar 24 (1898) 1-39.

31. Ho Y-S, McKay G. Kinetic models for the sorption of dye from aqueous solution by wood. Process Safety and Environmental Protection 76(2) (1998) 183-191.

32. Langmuir I. The adsorption of gases on plane surfaces of glass, mica and platinum. Journal of the American Chemical society 40(9) (1918) 1361-1403.

33. Freundlich H. Über die adsorption in lösungen. Zeitschrift für physikalische Chemie 57(1) (1907) 385-470.

34. Radushkevich MDL. The equation of the characteristic curve of the activated charcoal USSR Phys. Chem Sect 55(1947) 331. 